\title{
Correspondence
}

\section{Benign paroxysmal torticollis in infancy}

Sir,

I read with interest the paper by Deonna and Martin. ${ }^{1}$ The syndrome may be a separate and new clinical syndrome, but we can only be certain if such patients are carefully screened for possible medication. It is essential to consider the differential diagnosis of a drug-induced dystonia. We have drawn attention to this problem previously. ${ }^{2} 8$

The statement made by Deonna and Martin that benign paroxysmal torticollis is 'unlike any other known form of intermittent torticollis' is not sufficiently substantiated. Their criteria do not exclude drug-induced torticollis. Case 3, reported by us in $1970,{ }^{4}$ fulfilled all these criteria (except for the patient's age), but was caused by metoclopramide. Our patient was aged $7 \frac{1}{2}$ years, but even an infant may be given dystonia-inducing drugs and generally the parents do not tell us unless we ask. The symptoms and signs of 'paroxysmal torticollis' are strikingly similar to those of drug-induced dystonia. They include abnormal rolling of the eyes (oculogyric crisis), retrocollis, curved trunk (tortipelvis), and neck pain. The clinical picture is too complex to be described with the restrictive label of paroxysmal torticollis. All patients with a paroxysmal torticollis need a detailed history, searching for dystonia-inducers. Experience taught us that enumerating these drugs for the parents (phenothiazines, butyrophenones, metoclopramide, etc.) is essential and that denial by them does not exclude this aetiology. In addition, careful observation and an accurate description of all accompanying symptoms are mandatory. Only by so doing will we help our patients, and contribute to clarifying the cause of these symptoms.

\section{References}

1 Deonna T, Martin D. Benign paroxysmal torticollis in infancy. Arch Dis Child 1981; 56: 956-9.

2 Casteels-Van Daele M. Letter: Paroxysmal torticollis in infancy. Am J Dis Child 1970; 120: 88.

3 Casteels-Van Daele M. Letter: Benign paroxysmal torticollis in infancy. Acta Paediatr Scand 1979; 68: 911-2.

4 Casteels-Van Daele M, Jaeken J, Van der Schueren P, Zimmerman A, Van den Bon P. Dystonic reactions in children caused by metoclopramide. Arch Dis Child 1970; 45: 130-3.

Maria Casteels-Van Daele Department of Paediatrics, Academisch Ziekenhuis Gasthuisberg, University of Leuven, B-300 Leuven, Belgium
Dr Deonna comments:

We agree that drug-induced acute dystonia, like many other conditions, should be included in the differential diagnosis of any paroxysmal postural abnormality in infants and children. We also agree that failure to obtain a positive history of drug ingestion (as in our cases) does not exclude this possibility. New drugs which are potential 'dystonia-inducers' are increasingly used in babies with gastrointestinal reflux, at an age when benign paroxysmal torticollis often starts. This was recently reported from our department. ${ }^{1}$

However, the postural abnormality seen in benign paroxysmal torticollis remains throughout the course of the attack and, unlike dystonic spasms due to a drug reaction, ${ }^{12}$ does not seem to fluctuate. If one has not had the opportunity to observe the child carefully during the attack the recurrence of identical symptoms over many months in the absence of drug ingestion is the other strong argument in favour of benign paroxysmal torticollis. We have also paid attention to the other symptoms reported in association with paroxysmal torticollis and have been struck more by the presence of systemic disturbances (pallor, vomiting, pain) than by extrapyramidal signs.

Although we agree that the numerous causes of symptomatic torticollis should be ruled out before making the diagnosis of benign paroxysmal torticollis, enough clinical evidence has now accumulated to recognise it as a separate and new clinical syndrome of unknown, possibly diverse, aetiologies including migraine.

\section{References}

1 Sol P, Pelet B, Guignard J P. Letter: Extrapyramidal reactions due to domperidone. Lancet 1980 ; ii: 802.

${ }^{2}$ Low L C K, Goel K M. Metoclopramide poisoning in children. Arch Dis Child 1980; 55: 310-2.

\section{Lipoatrophy in a patient on highly purified beef insulin}

Sir,

Lipoatrophy at injection sites was reported in $10 \%$ of diabetics treated with conventional insulin preparations, but it was more common in girls and in young patients. ${ }^{1}$ Treatment by the injection of monocomponent porcine insulin is the treatment of choice ${ }^{2}$ either into the periphery or centre of the atrophic sites, although the latter is painful. I think that lipoatrophy in a patient treated exclusively with highly purified beef insulin has not previously been reported.

A 4-year-old girl developed diabetes mellitus and was stabilised on highly purified beef insulin zinc suspension (Neulente (Wellcome) 14 units daily). Her diabetic 